\title{
Effectiveness of Bifidobacterium bifidum in Mediating the Clinical Course of Murine Rotavirus Diarrhea ${ }^{1}$
}

\author{
L. C. DUFFY, M. A. ZIELEZNY, M. RIEPENHOFF-TALTY, D. DRYJA, S. SAYAHTAHERI-ALTAIE,
} E. GRIFFITHS, D. RUFFIN, H. BARRETT, J. ROSSMAN, AND P. L. OGRA

Department of Pediatrics, Children's Hospital, School of Medicine and Biomedical Sciences /L.C.D., M.R.-T. S.S.-A.], Department of Social and Preventive Medicine, School of Medicine and Biomedical Sciences [L.C.D., M.A.Z.J, Department of Microbiology, School of Medicine and Biomedical Sciences [M.R.-T., D.D., E.G., D.R., H.B.J, and Department of Surgery and Otolaryngology, Children's Hospital, School of Medicine and Biomedical Sciences [J.R.], State University of New York, Buffalo, New York 14222; and Department of Pediatrics, University of Texas Medical Branch, Galveston, Texas 77550 [P.L.O.]

\begin{abstract}
Human Bifidobacterium sp strain bifidum (B. bifidum) was administered to BALB/c lactating mice $(n=58)$ and their litters ( $n=327$ pups) to evaluate the ingested strain's adherent properties and ability to inhibit murine rotavirus (MRV) infection. ELISA and anaerobic bacteriologic techniques were used to measure MRV shedding and colonization of Bifidobacterium in the small intestine. At 13-16 d gestation, pregnant dams (and their expected litters) were randomly assigned to one of four experimental groups: 1) normal controls; 2) B. bifidumtreated only; 3) MRV-infected only; and 4) B. bifidumtreated + MRV-infected dams and litters. During the acute phase of diarrhea, $80 \%$ of small-intestine cultures in $B$. bifidum-treated litters were positive for the ingested $B$. bifidum strain compared with $24 \%$ of fecal cultures. Examination of tissue cross sections under electron microscopy revealed the ingested $B$. bifidum strain survived passage through the upper gastrointestinal tract and adhered to the small-intestine epithelium. After the administration of the high dose of virus, diarrhea developed in all pups, but onset was significantly delayed in $B$. bifidum-treated + MRV-infected litters compared with litters infected with MRV only $(p<0.02)$. B. bifidum-treated + MRV-infected pups demonstrated a significant reduction in MRV shedding compared with litters challenged with MRV only at d 2 to 10 after inoculation $(p<0.009)$. More direct studies are needed to assess mechanisms by which this anaerobe can alter the course of MRV infection at the level of gut epithelium. (Pediatr Res 35: 690-695, 1994)
\end{abstract}

\section{Abbreviations}

MRV, murine rotavirus

The biologic mechanisms underlying the interactions between the normal microbial flora and infectious challenge by enteric pathogens remain poorly understood. A number of virulence

Received July 19, 1993; accepted January 12, 1994.

Correspondence and reprint requests: Linda C. Duffy, Ph.D. Assistant Professor of Pediatrics, Children's Hospital, SUNY, 219 Bryant St., Buffalo, NY 14222.

Supported in part by research grants from the National Institute of Allergy and Infectious Diseases (AI 15939-08) and the J.H. Cummings Foundation Inc., Buffalo, New York.

' Presented in part at the American Pediatric Society-Society of Pediatric Research (APS-SPR) Annual Meeting in Washington, DC, May 1993. factors (crypt cell proliferation, cellular invasion, mucosal atrophy, enterotoxins, and cytotoxins) are all mechanisms by which enteropathogens cause diarrheal disease (1). Studies in our laboratories $(2)$ and elsewhere $(3,4)$ have focused on the potential benefit of commensal bacteria used as nutritional supplements to restore impaired bowel mucosal integrity and function in acute and persistent diarrhea states.

Both breast-fed and bottle-fed neonates receive generous amounts of gram-positive anaerobes during vaginal delivery (5). Putative antimicrobial components in human milk (glycolipids, glycoproteins, and oligosaccharides), and related milk factors (human milk acidic mucin complex) are thought to proliferate growth of the gram-positive Bifidobacterium bifidum variant $\mathrm{sp}$ pennsylvanicus in the gut of newborns fed breast milk $(6,7)$. Previously, we reported that clinical symptoms and duration of rotavirus gastroenteritis were significantly reduced in breast-fed infants, who demonstrated detectable levels of indigenous strains of this gram-positive anaerobe in feces at the time of infection (2). Recently, human milk mucin was shown to inhibit rotavirus replication in experimental gastroenteritis (7).

We hypothesized from our preliminary studies of ingested $B$. bifidum in human volunteers and animals (8) that the acidifying action and adherent properties by Bifidobacterium spp may be a possible mechanism by which the anaerobe alters viral replication or interferes with attachment of virus to intestinal epithelial cells. Another possible mechanism is supported by recent animal studies suggesting that the organism may also possess immunostimulating properties that mediate infectious challenge or prevent reinfection. Yamazaki et al. (9) found that germfree mice monoassociated with Bifidobacterium longum after a 4-wk period did not allow translocation of enteric pathogens to the internal organs. The augmentation of the humoral immune response after digestion of Bifidobacteria cell walls in guinea pigs has also been demonstrated (10).

The objectives of the present randomized blinded experiment were to examine whether oral administration of an ingested $B$. bifidum strain altered viral shedding in the small intestine and modified the clinical course of MRV diarrhea in BALB/c suckling mice.

\section{MATERIALS AND METHODS}

Study Design. Pregnant dams (13-16 d gestation) were obtained commercially (Charles River Laboratories, Portage, MI). Baseline fecal cultures tested negative for Bifidobacterium spp, and serologic tests were negative for anti-B. bifidum and antiMRV specific antibody. For the series of experiments performed, 
327 BALB/c pups in an average litter size of six pups were bred in our laboratories from the original stock. Pregnant dams $(n=$ 58) and their litters were randomly assigned to four experimental groups: I) normal controls; 2) B. bifidum-treated only; 3) pups infected with MRV alone; and 4) B. bifidum-treated + MRVinfected pups. All animal experiments were performed in accordance with the Department of Health and Human Services guidelines for the humane care and use of laboratory animals and approved by the SUNY Animal Care Committee.

Specimen Collection and Processing. As summarized in the experimental design shown in Table 1. B. bifidum-treated pups (groups 2 and 4 ) were orally administered $B$. bifidum suspended in sterile saline $\left(3 \times 10^{8}\right.$ colony-forming units $/ \mathrm{mL}$ ) (American Type Culture Collection, Rockville, MD) $24 \mathrm{~h}$ after birth through d 28 after delivery. Animals in the noninfected groups were administered B. bifidum (group 2) or sterile saline (group 1). Pups in the MRV-infected groups (groups 3 and 4) were inoculated on d 5 with the mouse MRV strain EDIM 5099, a group A mouse rotavirus (median infective dose $\left.2 \times 10^{7} / \mathrm{mL}\right)(20$ infectious doses in $10 \mathrm{~mL}$ ). Because of the high infectivity of $M R V$ in BALB/c mice, noninfected litters were kept in a separate room of the animal facility; none of the control mice experienced diarrhea.

Fecal specimens were collected twice weekly for all litters. Animal attendants observed a standardized protocol characterizing daily changes in clinical symptoms (dehydration, denuding, and lethargy), color and consistency of stools (watery, loose, and solid), and physical condition of the animals. Because diarrhea onset and resolution were variable for individual pups but did not represent independent observations, analysis was performed on litters. Hence, start of diarrhea for a litter was determined by the midpoint for individual pups in the litter. For the purpose of this analysis, time to onset of symptoms for a litter was defined as number of days postinoculation to the midpoint of start of diarrhea symptoms for individual pups in the litter. Similarly, time to recovery for a litter was defined as the duration of diarrhea symptoms (i.e. the time between the onset of diarrhea and midpoint of resolution for individual pups in the litter).

MRV disease in BALB/c suckling mice resembles the acute, self-limiting infection experienced in human infants and is a useful model for examining mucosal disease in the small intestine $(11,12)$. D $0,7,10,14$, and 21 were considered appropriate time points to examine clinical effects in the present experimental model. Individual pups from each experimental group (on average five to seven were randomly killed at the selected time points after MRV infection. Dams were prebled; serum and fecal specimens were collected before delivery and at $\mathrm{d} 0,7,10,14$, and 21 postinoculation for all litters. Additional experiments were

Table 1. Treatment and infection schedule by group

\begin{tabular}{|c|c|c|c|c|c|c|}
\hline \multirow[b]{2}{*}{ Experimental group } & \multicolumn{6}{|c|}{ Days after delivery* } \\
\hline & 1 & 2 & 3 & 4 & 5 & $6-28$ \\
\hline $\begin{array}{l}\text { Normal control } \\
\text { Dams } \\
\text { Pups } \\
\text { B. bifidum-treated only } \dagger\end{array}$ & & & & & & \\
\hline $\begin{array}{l}\text { Dams } \\
\text { Pups }\end{array}$ & B & $\begin{array}{l}\text { B } \\
\text { B }\end{array}$ & $\begin{array}{l}\text { B } \\
\text { B }\end{array}$ & $\begin{array}{l}\text { B } \\
\text { B }\end{array}$ & $\begin{array}{l}\text { B } \\
\text { B }\end{array}$ & $\begin{array}{l}\text { B } \\
\text { B }\end{array}$ \\
\hline $\begin{array}{l}\text { MRV-infected only } \neq \\
\text { Dams } \\
\text { Puns }\end{array}$ & & & & & & \\
\hline $\begin{array}{l}\text { Pups } \\
\text { B. bifidum + MRV-infected }\end{array}$ & & & & & MRV & \\
\hline $\begin{array}{l}\text { Dams } \\
\text { Pups }\end{array}$ & B & $\begin{array}{l}\text { B } \\
\text { B }\end{array}$ & $\begin{array}{l}\text { B } \\
\text { B }\end{array}$ & $\begin{array}{l}\text { B } \\
\text { B }\end{array}$ & $\begin{array}{c}\text { B } \\
\mathrm{B}+\mathrm{MRV}\end{array}$ & $\begin{array}{l}\text { B } \\
\text { B }\end{array}$ \\
\hline
\end{tabular}

* Dams and pups clinically followed up 0 through $28 \mathrm{~d}$ after delivery.

† B, Bifidobacterium; dams, $40 \mu \mathrm{L}$ of standardized suspension 1 st dose and $20 \mu \mathrm{L}$ on $\mathrm{d} 1-28$; pups, $10 \mu \mathrm{L} \mathrm{d} \mathrm{1-28.}$

$\ddagger$ Inoculum $10 \mu \mathrm{L}$ at $10^{-4}$ dilution of virus pool. performed on randomly selected (methoxyflurane) anaesthetized pups on $\mathrm{d} 2$ through 10 postinoculation to examine MRV shedding in the small intestine. Pups were weighed at death; bowel distention and intraluminal contents from anesthetized mice were noted before extraction of Peyer's patches and intestinal tissue for microbiologic and immunologic assays.

Cardiac or arterial blood was collected from anaesthetized animals. Blood was centrifuged, and serum aliquots were stored at $-20^{\circ} \mathrm{C}$. For experiments involving local intestinal tissue, the duodenum to distal ileum was removed. Assays were performed on Peyer's patches and minced, small-intestine tissue.

Laboratory Procedures. Isolation of anaerobes. Fecal and intestinal specimens were cultured anaerobically with fresh reduced, selective (Bifidobacterium spp) (13) and nonselective media (sheep blood agar). For these experiments, intestinal tissue from proximal duodenum to distal ileum including the ilealcecal junction was extracted. Tissue was placed in sterile saline ( $1 \mathrm{~mL})$, minced, and subsequently cultured under anaerobic conditions. Fecal specimens were suspended in $0.1-\mathrm{mL}$ sterile saline, vortexed, and cultured with a calibrated loop $(0.001 \mathrm{~mL})$.

Isolates confirmed to be gram-positive anaerobes were identified by gram stain (14) and rapid biochemical tests (ANA II System, Innovative Diagnostic Systems, Inc., Norcross, GA). For the full range of experiments, gas-liquid chromatography and the fructose-6-phosphate phosphoketalase enzyme test were used for speciation of Bifidobacterium. Sensitivity and specificity confirmatory testing was carried out in a blinded manner. The bacteriologic techniques developed are described in fuller detail in an earlier report (8).

Detection of $M R V$ virus-specific IgG in serum. MRV-specific IgG antibody levels in serum were determined with a modified ELISA. Briefly, plates were coated overnight with MRV and with MA 104 as control cells $(1 \mu \mathrm{g}$ protein $/ \mathrm{mL})$. After plates were incubated $(1 \mathrm{~h})$ with mouse serum to be tested, goat antimouse IgG horseradish peroxidase was added. The wells were extensively washed (three to four times) between incubations. $O$ phenylenediamine solution was then added as the substrate. The reaction was terminated with the addition of $1 \mathrm{~N} \mathrm{H}_{2} \mathrm{SO}_{4}$, and the optical densities were read at $492 \mathrm{~nm}$ with an enzyme immunoassay plate reader (Bio-Tek Instruments Inc., Burlington, VT).

Detection of rotavirus antigen. Intestinal tissue (proximal duodenum to distal ileum) extracted for detection of MRV replication was placed in sterile PBS (pH 7.4) in a ratio of $2 \mathrm{~mL} \mathrm{PBS/}$ $\mathrm{g}$ of tissue. Tissue was minced, flash frozen, and stored at $-70^{\circ} \mathrm{C}$. An adaptation of the double antibody sandwich ELISA method as described by Voller $e t$ al. (15) was used. In brief, rabbit antibody to human rotavirus was coated onto microtiter plates and incubated for $48 \mathrm{~h}$. Serum test samples were added and incubated for $2 \mathrm{~h}$ at $37^{\circ} \mathrm{C}$. After plates were washed, hyperimmune guinea pig antibody to MRV was added, and plates were incubated for $1 \mathrm{~h}$ at $37^{\circ} \mathrm{C}$. The plates were washed again, horseradish peroxidase-conjugated rabbit antibody to guinea pig IgG was added, and plates were again incubated. O-phenylenediamine was used as the enzyme substrate. The reaction was terminated by the addition of $1 \mathrm{~N} \mathrm{H}_{2} \mathrm{SO}_{4}$, and absorbance was measured at $492 \mathrm{~nm}$ with an enzyme immunoassay reader.

Enzyme-linked immunospot assay. The number of total IgAsecreting cells and MRV-specific IgA-secreting cells were determined by the solid-phase enzyme-linked immunospot method as described previously (16). In brief, Peyer's patch spleen and peripheral blood lymphocytes from the small intestine were extracted and harvested from $B$. bifidum-treated and nontreated MRV-infected animals at d 7,14 , and $21 \mathrm{~d}$ postinoculation. Spleens were minced and forced through a sterile steel mesh. The peripheral blood was heparinized and diluted 1:1 with cold Hanks' balanced salt solution. The heparinized peripheral blood and spleen was placed over Ficoll (Histopaque 1083, Sigma, St. Louis, MO) in their respective dilutions and centrifuged to separate lymphocytes. The lymphocytes were washed $3 \times$ in $5 \%$ FCS RPMI. After washing, red blood cells were lysed with 
ammonium chloride and then washed two more times. The lymphocyte pellets were resuspended in $1 \mathrm{~mL}$ of $5 \%$ FCS RPMI and quantitated on a hematocytometer.

Flat-bottomed 96-well microtiter plates were coated with rabbit antimouse IgA (for total IgA-secreting cells) and purified EDIM (for specific IgA-secreting cells) and stored overnight at $4^{\circ} \mathrm{C}$. Plates were washed with PBS (pH 7.4) and blocked with $5 \%$ FCS RPMI in a $37^{\circ} \mathrm{C} \mathrm{CO}$ incubator. Cell suspensions were placed in appropriate wells and incubated at $37^{\circ} \mathrm{C}$ for $3 \mathrm{~h}$. Plates were washed again with PBS and PBS-Tween $20(0.05 \%)$. Goat antimouse IgA horseradish peroxidase was then used as the conjugate and was added to the well and incubated overnight at $4^{\circ} \mathrm{C}$. Plates were extensively washed (three to four times) between incubations. Amino-9-ethylcarbazole and $\mathrm{N}$-dimethylformamide was used as the substrate for visualization of the spots. An immune response was defined as more than 0.5 specific IgAsecreting cells $/ 10^{6}$ cells.

Isolation of lymphocyte populations. Peyer's patches were prepared after a modified method developed by Frangakis et al. (17). Briefly, pooled patches were placed in warm RPMI 1640 media containing $100 \mathrm{IU} / \mathrm{mL}$ collagenase IV and mixed endover-end at $37^{\circ} \mathrm{C}$ for $1 \mathrm{~h}$. Partially digested patches were gently teased apart and mixed at $37^{\circ} \mathrm{C}$ for an additional $1 \mathrm{~h}$. The cell suspension was passed through a $20-\mu \mathrm{m}$ filter to remove large clumps and debris. Cells were washed two times in PBS and counted. Immunophenotypic analyses were performed by labeling $10^{6}$ cells with L3T4-PE versus Ia-FITC, LY5-PE versus IaFITC, LY5-PE versus IgG-FITC, and LY5-PE versus IgA-FITC and analyzed on a Coulter EPICS PROFILE II flow cytometer (Coulter, Hialeah, FL). Histograms plotting log green versus log red fluorescence were used to determine positive cell populations.

Statistical analyses. Clinical results including fecal and intestinal cultures represented pooled results within litters, not individual pups. MRV antigen results in intestinal tissue, however, was tested separately in individual pups. MRV antigen ELISA assays were run in one to three batches for a given day postinoculation. Each batch had its own standard (gradient purified tissue culture grown MRV) with several values of OD $(y)$ at corresponding titration values $[x=\mathrm{Ln}$ (titration)]. By scatterplotting values of $x$ against $y$, we identified the range of dilution values that best represented a straight line and ranged between detection levels of the assay $(0.10-1.0 \mu \mathrm{g} / \mathrm{mL})$. Logarithmic transformation ( $\operatorname{Ln} y$ ) was used to improve linearity and to assure correlation coefficients of at least 0.97 for each standard curve. Predicted ranges of OD were determined from the fitted regression lines. For further analysis, individual pup values were converted to micrograms of virus protein per gram of tissue and averaged. More details regarding the algorithms used are available on request.

Comparison of clinical progression and recovery rates for the two MRV-infected groups was based on litters with the use of a cumulative survival regression model (18). Litters at the time when all pups were killed were considered as censored data. Shedding of MRV in the small intestine (d 2 to 10 postinoculation) between the two MRV-infected groups was analyzed by repeated measures analysis of variance (19). All analyses were based on two-tailed tests.

\section{RESULTS}

Clinical Outcome. Altogether, 58 litters comprised the four experimental groups in the study, with 5.7 pups (on the average) per litter. Because litters were randomized to treatment group before delivery, weight and litter size were examined as potential covariables before further analyses were performed. The weight of pups at time of death differed significantly between noninfected litters (groups 1 and 2) and MRV-infected litters (groups 3 and 4) $(p<0.001)$ (Table 2). Denuding and weight loss in MRV-infected litters were similar to those reported in naturally acquired infection.
A typical litter (median) in the group infected with only MRV had $88 \%$ of pups with diarrhea by d 2 postinoculation. By contrast, only $50 \%$ of pups in a B. bifidum-treated + MRVinfected litter had diarrhea symptoms by $\mathrm{d} 2$ after inoculation. Time to onset of diarrhea illness for the two MRV-infected groups, with adjustment for censored data, is shown in Figure 1 as a cumulative percentage with diarrhea. The observed delay in clinical onset was statistically significant in $B$. bifidum-treated + MRV-infected litters compared with litters infected with MRV only $(p<0.02)$. Diarrhea onset in the group infected with only MRV typically ranged between 2 and $2.5 \mathrm{~d}$ after inoculation (25th and 75 th percentiles), with a mean of $2 \mathrm{~d}$. By contrast, onset of diarrhea illness in B. bifidum-treated + MRV-infected litters ranged between 2.5 and $3.5 \mathrm{~d}$ after inoculation, with a mean of $3 \mathrm{~d}$. Time to resolution for infected litters is shown in Figure 2. The resolution of illness was less predictable than was observed for diarrhea onset. The two recovery curves were similar, with estimated median time to resolution for both groups being $7 \mathrm{~d}$ (mean, $6.9 \mathrm{~d}$ ). Notably, diarrhea recovery began earlier in $B$. bifidum-treated + MRV-infected pups compared with litters challenged with MRV only, but duration of clinical illness from onset of symptoms was similar for both infected groups.

Adherence of B. bifidum Strains. As shown in Table 3, fecal and intestinal cultures from mice were examined for presence of $B$. bifidum-ingested strains. Of $B$. bifidum-treated litters tested (groups 2 and 4) during the acute phase of diarrhea, 11 of 45 (24\% sensitivity) fecal specimens were culture positive for $B$. bifidum. However, when minced small-intestine tissue was cultured, B. bifidum was isolated from eight of 10 (80\% sensitivity) specimens. The $B$. bifidum-ingested strain was isolated from fecal and intestinal cultures in both B. bifidum-treated groups; quantitation was highest in $B$. bifidum control animals. Closer examination of tissue cross sections under light microscopy and electron microscopy (Fig. 3) confirmed that the B. bifidumingested strain survived transit through the upper gastrointestinal tract, colonized, and adhered to the mucosal epithelium of the small intestine. The $B$. bifidum-ingested strain was not isolated from fecal specimens or the intestinal mince from the nontreated litters (100\% specificity for groups 1 and 3 ).

Virus Shedding. In a separate set of experiments, we examined whether the ingested $B$. bifidum strain, which was shown by electron microscopy to adhere to gut mucosa and was associated with delayed clinical onset of MRV diarrhea, may have interfered with shedding of virus. MRV shedding in the small intestine of individual pups in MRV-infected litters was measured daily for d 2-10 postinoculation. The number of pups tested ranged from three to seven for each of the two MRV-infected groups (groups 3 and 4 ) for each day of the experiment. As shown in Figure 4, when differences in MRV shedding at d 2-10 postinoculation were tested by an analysis of variance with repeated measures, a significant $B$. bifidum treatment effect $(p<0.009)$ and effect of treatment by day postinoculation $(p<0.0001)$ was evident. No interactive effect between treatment and day was found. In contrast, elevated MRV-IgG serum antibody titers correlated well in MRV-infected dams and their respective litters, but no difference in systemic response to MRV was noted between the two groups of infected mice.

To examine the possibility that immune mechanisms might be involved in the reduction of MRV shedding observed, we used the enzyme-linked immunospot assay and additional immunophenotypic techniques to measure the gut immune response in Ig-secreting Peyer's patch cells. The number of total IgA antibody secreting cells in $B$. bifidum-treated mice was greater than for the nontreated MRV-infected group at $d 7$ postinoculation (data not shown), but the difference was not statistically significant. Similar results were found for the number of anti-rotavirus IgA antibody secreting cells in the $B$. bifidumtreated groups compared with mice challenged with MRV only.

With the use of flow cytometric techniques, increased but nonsignificant $\operatorname{IgA}$ and $\operatorname{IgG}$ antibody responses were found in 
Table 2. Mean and SD of physiologic characteristics by treatment group

\begin{tabular}{|c|c|c|c|c|c|}
\hline \multirow[b]{2}{*}{ Group } & \multirow[b]{2}{*}{$\begin{array}{l}\text { No. of } \\
\text { litters }\end{array}$} & \multirow[b]{2}{*}{$\begin{array}{c}\text { No. of } \\
\text { pups }\end{array}$} & \multicolumn{3}{|c|}{ Physiologic characteristics } \\
\hline & & & Litter size & $\begin{array}{l}\text { Age at death } \\
\text { (d) }\end{array}$ & $\begin{array}{l}\text { Pup weights } \\
(\mathrm{g})^{*}\end{array}$ \\
\hline Normal control & 10 & 60 & $6.0 \pm 2.5$ & $10.3 \pm 6.7$ & $8.6 \pm 3.4$ \\
\hline B. bifidum-treated only & 10 & 52 & $5.2 \pm 2.2$ & $8.9 \pm 6.4$ & $7.9 \pm 3.1$ \\
\hline MRV-infected only & 19 & 111 & $5.8 \pm 1.4$ & $8.4 \pm 6.1$ & $7.0 \pm 2.7$ \\
\hline B. bifidum + MRV-infected & 19 & 104 & $5.5 \pm 1.1$ & $8.6 \pm 6.0$ & $7.1 \pm 2.6$ \\
\hline Total & 58 & 327 & $5.7 \pm 1.8$ & $8.9 \pm 6.3$ & $7.5 \pm 3.0 \dagger$ \\
\hline
\end{tabular}

* Pup weight was calculated at time of autopsy and therefore relates to age and litter size.

+ Analysis of variance comparisons in mean pup weights significantly higher $(p<0.05)$ in normal and positive $B$. bifidum control pups compared with MRV-infected litters.

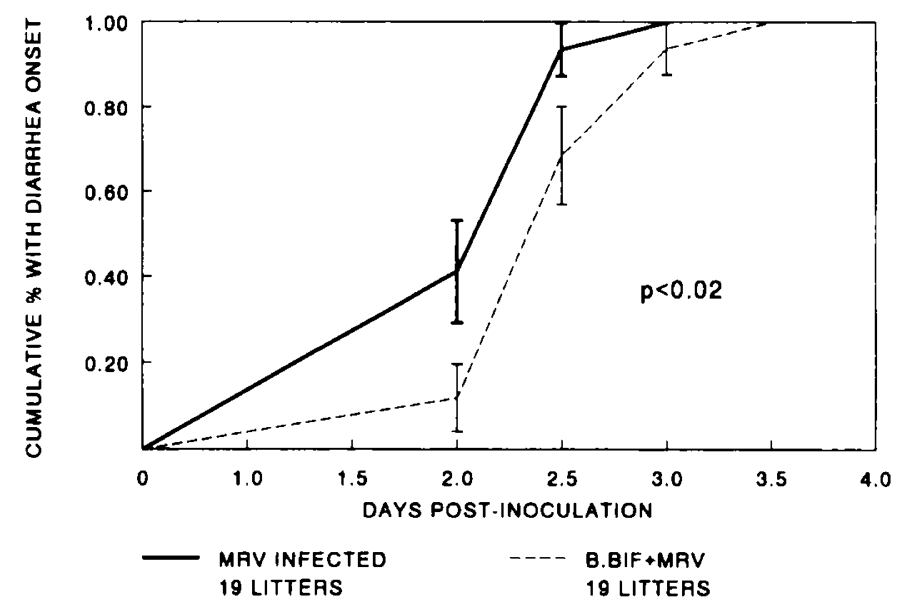

Fig. 1. Onset of diarrhea illness in MRV-infected litters $(n=19)$ vs B. bifidum-treated + MRV-infected $(n=19) \mathrm{Balb} / \mathrm{c}$ mice: level of significance, $p<0.02$.

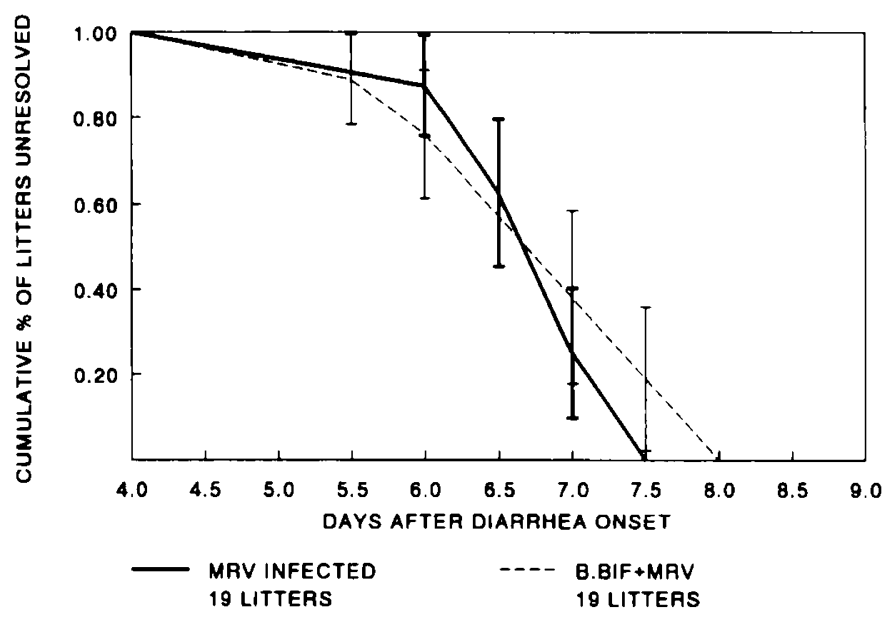

Fig. 2. Resolution of diarrhea illness in MRV-infected litters $(n=19)$ vs B. bifidum-treated + MRV-infected $(n=19)$ Balb/c mice; $p$ value nonsignificant.

intestines of $B$. bifidum-treated pups compared with pups challenged with MRV only. Double labeling of lymphocytes revealed only minimal association of the class II la activation marker with the T-cell population. The presence of Ia + cells was, therefore, assumed to be the result of B-cell activation. Furthermore, the LY5 (B220) marker was derived from clone RA3-6B2, which recognizes a B-cell-restricted determinant expressed on mouse $B$ and pre-B cells. Clonal expansion of IgG on B cells could not be interpreted as anti- $B$. bifidum or anti-MRV specific, although the low immunogenicity of $B$. bifidum as circulating antibody suggests an MRV-specific IgG response was stimulated. The cellular immune responses observed in these preliminary exper-
Table 3. Sensitivity and specificity of B. bifidum isolates

\begin{tabular}{lccc}
\hline & $\begin{array}{c}\text { No. of } \\
\text { pups }\end{array}$ & $\begin{array}{c}\text { Sensi- } \\
\text { tivity } \\
(\%)\end{array}$ & $\begin{array}{c}\text { Speci- } \\
\text { ficity } \\
(\%)\end{array}$ \\
\hline $\begin{array}{l}\text { Fecal culture } \\
\text { B. bifidum-treated } \dagger \text { (groups 2 and 4) }\end{array}$ & 45 & 24 & \\
$\quad \begin{array}{l}\text { Nontreated (groups 1 and 3) } \\
\text { Intestinal culture† }\end{array}$ & 47 & & 100 \\
B. bifidum-treated (groups 2 and 4) & 10 & 80 & \\
$\quad$ Nontreated (groups 1 and 3) & 10 & & 100 \\
\hline
\end{tabular}

* $B$. bifidum-treated group included $B$. bifidum only and MRV. infected $+B$. bifidum-treated groups.

$\dagger$ Culture taken from small intestine, cecum, and large-intestine mince at time of autopsy.

iments must be interpreted cautiously, but the potential adjuvant properties of $B$. bifidum against MRV antigen warrant closer examination.

\section{DISCUSSION}

The results of the present study indicate that $B$. bifidum therapy is effective in altering the clinical course of experimental gastroenteritis. Of particular relevance, throughout the days postinfection reported for these experiments, the B. bifidum + MRVinfected group consistently demonstrated MRV antigen levels below those shown for the litters infected with MRV only $(p<$ 0.009 ). Although the difference varied somewhat for given days postinfection, the consistency of the finding is further noted by the nonsignificant interactive effect (treatment, day) reported.

Although the exact mechanism is unclear, binding of the ingested $B$. bifidum strain to intestinal epithelial cells may be affecting reduction in virus shedding so that viral replication is decreased, cytopathic effect is altered, or viral attachment itself is impeded. Decreased shedding could also be a result of immune system effects, differences in number of infected cells, or changes in rate of viral release. More direct studies will be needed to assess the anaerobes adherent properties and whether $B$. bifidum is a mucosally active adjuvant at the level of the gut epithelium.

Daily supplementation with the $B$. bifidum strain revealed no adverse or toxic effects. The observed delay in acute diarrhea onset may bear important implications on mediating virus shedding and in preventing rotavirus diarrhea in animal and human hosts. Recovery for both groups of infected mice was somewhat influenced by the high dose of MRV inoculum given. Further experiments examining attenuation of clinical disease after augmented supplementation with $B$. bifidum and lowered virus dose are needed.

The duration of diarrhea, clinical picture, and reduction in viral shedding in the intestinal epithelium is in keeping with previous animal and human studies $(12,20)$. It is unlikely that the observed dissimilarities in the MRV-infected litters compared with $B$. bifidum-treated + MRV-infected litters could be explained by preexisting differences between the groups. The age 


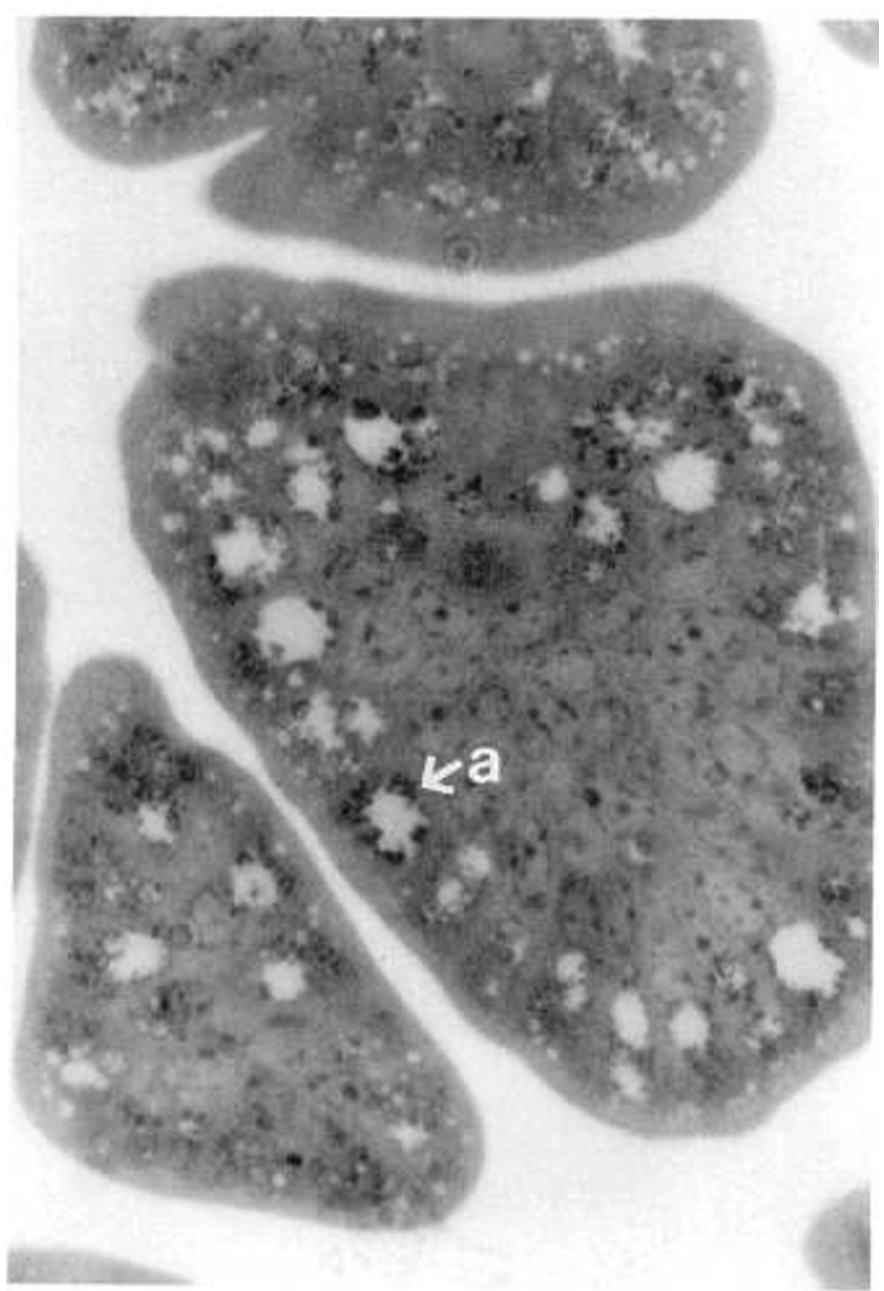

Fig. 3. Colonies of gram-positive ingested B. bifidum strain $(a)$ can be seen in the gut epithelium (oil immersion).

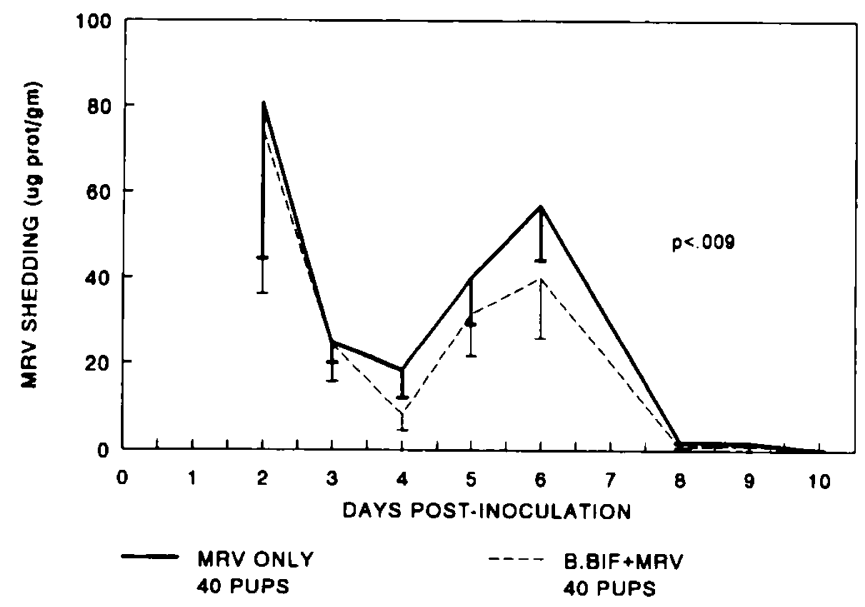

Fig. 4. MRV shedding (ug/protein/gm) days postinoculation in MRV-infected litters $(n=40)$ vs B. bifidum-treated + MRV-infected ( $n$ $=40) \mathrm{Balb} / \mathrm{c}$ mice; $p$ value $<0.009$.

distribution of pups were preassigned before death and were therefore comparable for all treatment groups. Furthermore, weight and litter size were similar in both of the MRV-infected groups. Thus, none of these potential confounding influences explained the difference in the clinical picture at the acute and recovery phases of diarrhea presented in this report.

It is well established that rotavirus has tropism for the epithelial enterocytes of the gut (21). Our findings tentatively suggest that
B. bifidum may interfere with replication or attachment and uptake of virus through Peyer's patches. Alternatively, previous in vivo studies have demonstrated that human Peyer's patches are well developed early in fetal life, and yet it takes a few weeks after birth before activated lymphoid follicles appear in the intestine (22). It is conceivable that priming the intestine with $B$. bifidum may be a mucosally active adjuvant to enhance gut immune responses against rotavirus antigen. Our preliminary data (unpublished) provides only weak evidence that $B$. bifidum treatment influenced IgA-and IgG-committed B-cell populations in this mouse model. Nevertheless, we speculate that augmented treatment with $B$. bifidum with lowered MRV challenge may influence permeation of MRV antigen through Peyer's patch lymphocytes, and proliferation of Ig-committed B-cell responses. Additional studies are needed, but our findings reported here are consistent with a previous report by our laboratories (23) suggesting a close relationship between the availability of MRV antigen in the lymphoid follicles at different locations in the gutassociated lymphoid tissues and development of a secretory IgA antibody response essential to clinical recovery.

The possibility that $B$. bifidum may be a mucosally active adjuvant is tenuously supported by the finding that it was difficult to induce serum anti-B. bifidum antibody in mice administered $B$. bifidum for $21 \mathrm{~d}$. MRV-specific $\mathrm{IgG}$ antibody in serum, on the other hand, was shown in concurrent experiments to be detected after a single oral dose of murine rotavirus. Hence, it was demonstrated that $B$. bifidum was a weakly immunogenic antigen. Similarly, anti-B. bifidum IgA antibody in the intestinal wash was at higher detectable levels than in serum; nevertheless, it was hard to induce antibody, and the response remained at relatively low levels throughout the experiments. These results are in general agreement with another recently published report $(10)$ indicating it is unlikely that $B$. bifidum produces hypersensitivity responses after ingestion of the organism in mice.

In summary, the findings presented in this report suggest that potential adherent or immunostimulating properties of ingested B. bifidum strains may offer alternative therapeutic approaches against infectious challenge by enteropathogens. More direct studies are needed to assess possible mechanisms by which this anaerobe can alter the course of MRV infection at the level of gut epithelium.

\section{REFERENCES}

1. Mims CA 1987 Mechanisms of cell and tissue damage. In: The Pathogenesis of Infectious Disease. Academic Press, New York, pp 179-224

2. Duffy LC, Riepenhoff-Talty M, Byers TE, Zielezny MA, Dryja D, Ogra PL 1986 Modulation of rotavirus enteritis during breast feeding. Am J Dis Child 140:1164-1168

3. Yamazaki S, Machii K, Ueda K, Momose H. Tsuyuki S, Kawashima T 1985 Immune responses to monoassociated Bifidobacterium longum in mice. In: Yamazaki S, Kawashima T (eds) Germfree Research: Microflora Control and Its Application to the Biomedical Sciences. Alan Liss Inc. New York, pp 399-401

4. Kaila M, Isolauri E, Soppi E, Virtanen E, Laine S, Arvilommi H 1992 Enhancement of the circulating antibody secreting cell response in human diarrhea by a human Lactobacillus strain. Pediatr Res 32:141-144

5. Bullen CL. Tearle PV. Willis AT 1976 Bifidobacteria in the intestinal tract of Infants: an in vivo study. J Med Microbiol 9:325-327

6. Rasic JL, Kurmann JA 1983 Bifidobacteria and Their Role. Birkhauser Verlag. Boston, pp 1-158

7. Yolken R, Peterson J, Vonderfcht SL, Fouts ET, Midthun K, Newberg, DS 1992 Human milk mucin inhibits rotavirus replication and prevents experimental gastroenteritis. J Clin Invest 90:1984-1991

8. Duffy LC. Zielezny MA. Dryja D, Faden H, Ogra PL 1992 Bifidobacterium colonization of the human intestine: cultivation and characterization of resident and ingested strains. In: Lonnerdal B, Picciano M (eds) Mechanisms Regulating Lactation and Infant Nutrient Utilization. Wiley-Liss Inc. New York, pp 383-387

9. Yamazaki S, Machii K. Tsuyuki S, Momose H, Kawashima T, Udea K 1985 Immunological responses to monoassociated Bifidobacterium longum and their relation to prevention of bacterial invasion. Immunology 56:43-47

10. Yasui H, Mike A. Ohwaki M 1989 Immunogenicity of Bifidobacterium breve and change in antibody production in Peyer's patches after oral administration. J Dairy Sci 72:30-35

11. Riepenhoff-Talty M, Lee PC, Carmody PJ, Barrett HJ, Ogra PL 1982 Age- 
dependent rotavirus-enterocyte interactions. Proc Soc Exper Biol Med 70:146-154

12. Uhnoo IS. Friehorst J, Riepenhoff-Talty M 1990 Effect of rotavirus infection and malnutrition on update of a dietary antigen in the intestine. Pediatr Res 27:153-160

13. Beerens H 1990 An elective and selective isolation medium for Bifidobacterium spp. Lett Appl Microbiol 11:155-157

14. Scardovi V 1986 Genus Bifidobacterium. In: Sneath P (ed) Bergey's Manual of Systematic Bacteriology, Vol 2. Williams \& Wilkins, Baltimore, p 1418

15. Voller AD, Bidwell E, Bartlett A 1976 Microplate enzyme immunoassays for the immunodiagnosis of virus infections. In: Rose N. Friedman W (eds) Manual of Clinical Immunology. American Society of Microbiology, Washington, DC, pp 506-508

16. Czerekinsky CC 1988 Microplate enzyme immunoassays for immunodiagnosis of virus infections. J Immunol Methods 115:31-37

17. Frangakis MV, Koopman WJ, Kiyono H, Michalek SM, McGhee JR 1982 An enzymatic method for preparation of dissociated murine Peyer's patch cells enriched for macrophages. J Immunol Methods 48:33-35

18. Meinert CL 1986 Clinical Trials: Design, Conduct and Analysis. Oxford University Press, New York, pp 188-192

19. Everitt BS 1989 Statistical Methods for Medical Investigations. Oxford University Press, New York, pp 83-98

20. Grimwood K, Lund JS, Coulson BS, Hudson IL. Bishop RF. Barnes GL 1988 Comparison of serum and mucosal antibody responses following acute rotavirus gastroenteritis in young children. J Clin Microbiol 26:732-738

21. Brandtzaeg P, Baklien K, Bjerke K, Rognum TO, Scott H, Valnes K 1987 Enteric infection and gut immunity. In: Miller K, Nicklin S (eds) Immunology of the Gastrointestinal Tract. Vol 1. CRC Press Inc, Boca Raton. FL, pp $1-85$

22. Ogra PL, Greene HL 1982 Human milk and breast feeding: an update on the state of the art. Pediatr Res 16:266-271

23. Dharakul T, Riepenhoff-Talty M. Albini B, Ogra PL 1988 Distribution of rotavirus antigen in intestinal lymphoid tissues: potential role in development of the mucosal immune response to rotavirus. Clin Exp Immunol 74:14-19 